Mexican Journal of Biotechnology 2020, 5(3):83-98

Journal homepage:www.mexjbiotechnol.com

ISSN:2448-6590

ORIGINAL RESEARCH

\title{
Fatty acid profile variability in Jatropha curcas oil and their use as varietal descriptors
}

\section{Variabilidad del perfil de ácidos grasos en aceite de Jatropha curcas y su uso como descriptores varietales}

Juan Ubaldo Sánchez-Velázquez, Jesús Alfonso Patrón-Vázquez, Neith Pacheco, Guadalupe Lopez-Puc, Ana Ramos-Díaz*

Subsede Sureste. Centro de Investigación y Asistencia en Tecnología y Diseño del Estado de Jalisco A. C. Tablaje Catastral 31264 Km 5.5 Carretera Sierra PapacalChuburna Puerto Parque Científico Tecnológico de Yucatán CP: 97302 Mérida, Yucatán, México

${ }^{*}$ Corresponding author

E-mail address: aramos@ciatej.mx (A. Ramos-Díaz)

Article history:

Received: 3 April 2020 / Received in revised form: 22 June 2020 / Accepted: / 24 June 2020 / Published online: 1 July 2020.

https://doi.org/10.29267/mxjb.2020.5.3.83

\section{ABSTRACT}

Because of its fatty acid profile (FAP) Jatropha curcas seed oil is considered suitable to produce biodiesel. FAP indicates the presence and proportion of different fatty acids such as oleic acid, linoleic acid, palmitic acid, and stearic acid. However, the FAP is variable between populations of the same species, therefore the quality of the biodiesel produced varies from one accession to another. Different genetic improvement programs select and cross plants to improve seed yield, nonetheless, it is necessary to obtain new varieties with the appropriate FAP for high-quality biodiesel production. In the present work, the variability of the FAP of 24 accessions ( 6 parents and 3 controls and 15 F1 hybrids) was evaluated, as well as the use of fatty acids as chemical descriptors. The FAP was determined by GC-MS chromatography, their variability and interdependence were evaluated to establish the fatty acids (or the relationship among them) that could be used as trait. Finally, a method is proposed to assign trait states considering the variability of the character value, for use as a varietal chemical descriptor.

Keywords: Fatty acids, Jatropha curcas, varietal descriptors. 


\section{RESUMEN}

Debido a su perfil de ácidos grasos (FAP) el aceite de la semilla de Jatropha curcas se considera adecuado para la producción de biodiesel. FAP se refiere al presencia y proporción de diferentes ácidos grasos como ácido oleico, acido linoleico, ácido palmítico y ácido esteárico. Sin embargo, el FAP es variable entre poblaciones de una misma especie, por lo que la calidad del biodiesel producida varia de una accesión a otra. Diferentes programas de mejoramiento genético seleccionan y cruzan plantas para aumentar el rendimiento de la semilla, no obstante, es necesario obtener nuevas variedades con el FAP adecuado para producción de biodiesel de alta calidad. En el presente trabajo, la variabilidad de los FAP de 24 accesiones (6 parentales y 3 testigos y 15 híbridos F1) fue evaluada, así como la utilización de los ácidos grasos como descriptores químicos. Los FAP fueron determinados por cromatografía GC-MS, su variabilidad y su interdependencia fueron evaluadas para establecer los ácidos grasos (o la relación entre ellos) que podrían usarse como caracteres. Por último, se propone un método para asignar estados de caracter considerando la variabilidad del valor del carácter, para su uso como descriptor químico varietal.

Palabras clave: Acidos grasos, descriptores varietales, Jatropha curcas.

\section{INTRODUCTION}

Jatropha curcas is an oleaginous plant species that are used to produce oil as a raw material for biodiesel manufacture (Teo et al., 2019). Its oil has physicochemical characteristics that allow it to produce high-quality biodiesel, such as its cetane number $(\mathrm{CN}>47)$ and oxidative stability $(>6 \mathrm{~h}$ ) (Ong et al., 2011; Sivaramakrishnan \& Ravikumar, 2012). These characteristics are directly associated with the fatty acid profile (FAP) of the oil since saturated fatty acids increase the values of $\mathrm{CN}$ and reduce oxidative stability, while unsaturated fatty acids reduce $\mathrm{CN}$ and increase oxidative stability (Ramos et al., 2009; Rashed et al., 2015). Few studies have proposed the relationship between FAP and produce high quality of biodiesel, FAP should have a predominance of monosaturated oil and a low proportion of polyunsaturated oils to ensure the high quality of biodiesel (Ramos et al., 2009; Nakkash \& Al-karkhi, 2012).

The characterization of $J$. curcas oil from different parts of the world has shown that the species exhibits a wide variation in the FAP. The predominant fatty acids are oleic acid (28.3\% to $63 \%$ ) and linoleic acid (19\% to $43 \%$ ); other acids that are present in proportions above $5 \%$ are palmitic acid $(7 \%$ to $13.6 \%)$ and stearic acid (5.2\% to 9.7\%) (Rodrigues et al., 2013; Montes et al., 2014; Cruz Rubio et al., 2015; Shalaby, 2015). The characterization of FAP of vegetable oil, and the use of the profile as a differentiating trait (descriptor) between accessions, is thus an important element in the development of the most suitable plant varieties for the production of biodiesel (King et al., 2009). 
This type of descriptor has been used in oleaginous plants to select varieties and improve the properties of the vegetable oil produced. Previous works have characterized two peanuts (Arachis hypogaea) varieties to select the one with the highest content of oleic acid and the lowest content of linoleic acid, to improve the oxidative stability of the oil produced (O'Keefe et al. 1993). Different authors have developed strategies to increase the proportion of oleic and linoleic acid in canola (Brassica napus) to produce an edible vegetable oil of better nutritional quality (Broglie et al., 2006; Beyzi et al., 2019). Furthermore, there are reports of sunflower varieties (Helianthus annuus) whose oil has a proportion of oleic acid that ranges from $24.6 \%$ to $89.3 \%$, while the proportion of linoleic acid is higher in varieties with lower amounts of oleic acid (64.7\%), and lower in those that contain a greater amount of oleic acid (4\%) (de Carvalho et al., 2019).

In J. curcas, unlike peanut, canola, and sunflower plants, the variability in the composition of fatty acids has not been considered as a descriptor, even though the biodiesel produced from different varieties and accessions of J. curcas has different physicochemical properties depending on that FAP. Although the FAP description of $J$. curcas has been described by different authors, the methodology for using this composition as a descriptor has not been evaluated for genetic improvement programs. The aim of the present work was to determine the variability of the FAP in different $J$. curcas accessions and to evaluate the use of these profiles as descriptors for distinguishing among accessions in genetic improvement programs focused on developing J. curcas varieties specialized in the production of oil with high concentrations of specific oleic acid.

\section{MATERIALS AND METHODS}

\subsection{Plant material}

An experimental plantation of 24 accessions of Jatropha curcas was established in Yucatan, Mexico $21^{\circ} 08$ '00.7 "N 89 ${ }^{\circ} 46^{\prime}$ 49.6" W), the crop was started with 15 stakes per accession from a jatropha germplasm bank (Agroindustria Alternativa del Sureste SPR de RL de CV). Nine accessions were collected by the company from different regions, of which six were used as parental accessions JatroP1, JatroP2, JatroP3, JatroP4, JatroP5, JatroP6; three accessions were used as a control to define a better separation of crosses from parents: JatroT1, JatroT2, and JatroT3. And 15 accessions are crosses: JatroC1, JatroC2, JatroC3, JatroC4, JatroC5, JatroC6, JatroC8, JatroC8, JatroC8, JatroC12, JatroC13, JatroC14, and JatroC15 (Table 1). After one year, fully ripe fruits were harvested, and the nuts were extracted from the seeds by breaking the testa manually. They were then stored at $4^{\circ} \mathrm{C}$ until use. 
Table 1. Description of the J. curcas accessions used.

\begin{tabular}{lllll}
\hline Accession & $\begin{array}{l}\text { Type of } \\
\text { accession }\end{array}$ & Origin & $\begin{array}{l}\text { Female } \\
\text { parental }\end{array}$ & Male parental \\
\hline JatroP1 & Parental & Nicaragua & N.A. & N.A. \\
JatroP2 & Parental & Nicaragua & N.A. & N.A. \\
JatroP3 & Parental & Chiapas & N.A. & N.A. \\
JatroP4 & Parental & Chiapas & N.A. & N.A. \\
JatroP5 & Parental & Veracruz & N.A. & N.A. \\
JatroP6 & Parental & Chiapas & N.A. & N.A. \\
JatroT1 & Control & Veracruz & N.A. & N.A. \\
JatroT2 & Control & Chiapas & N.A. & N.A. \\
JatroT3 & Control & Yucatan & N.A. & N.A. \\
JatroC1 & Cross & N.A. & JatroP1 & JatroP2 \\
JatroC2 & Cross & N.A. & JatroP5 & JatroP2 \\
JatroC3 & Cross & N.A. & JatroP2 & JatroP4 \\
JatroC4 & Cross & N.A. & JatroP1 & JatroP4 \\
JatroC5 & Cross & N.A. & JatroP1 & JatroP5 \\
JatroC6 & Cross & N.A. & JatroP2 & JatroP6 \\
JatroC7 & Cross & N.A. & JatroP1 & JatroP6 \\
JatroC8 & Cross & N.A. & JatroP2 & JatroP3 \\
JatroC9 & Cross & N.A. & JatroP1 & JatroP3 \\
JatroC10 & Cross & N.A. & JatroP4 & JatroP5 \\
JatroC11 & Cross & N.A. & JatroP4 & JatroP6 \\
JatroC12 & Cross & N.A. & JatroP4 & JatroP3 \\
JatroC13 & Cross & N.A. & JatroP5 & JatroP6 \\
JatroC14 & Cross & N.A. & JatroP5 & JatroP3 \\
JatroC15 & Cross & N.A. & JatroP6 & JatroP3 \\
\hline NA.:Not & & & &
\end{tabular}

N.A.: Not applicable

\subsection{Oil extraction and analysis of FAP}

The fractionated kernels $(120 \mathrm{~g})$ were dried for $1 \mathrm{hr}$. at $60{ }^{\circ} \mathrm{C}$; subsequently, samples were placed in a hydraulic press and subjected to a force of $2 \mathrm{Ton} / \mathrm{m}$ for 5 min. The oil was collected and centrifuged at $6000 \mathrm{~g}$ for $10 \mathrm{~min}$ to remove solid residues. The oil obtained was stored in the dark at $-20^{\circ} \mathrm{C}$ until further analysis.

Acidic esterification was carried out according to Ichihara \& Fukubayashi protocol (2010) with the following modifications, oil samples were diluted at $5000 \mathrm{ppm}$ in 1 $\mathrm{ml}$ of hexane, $7.5 \mathrm{ml}$ of methanol and $1.5 \mathrm{ml}$ of $\mathrm{HCl}(8 \%$ in methanol) was added. The samples were then vigorously shaken for $10 \mathrm{sec}$. Subsequently, transesterification was carried out by heating the samples at $100{ }^{\circ} \mathrm{C}$ for $1.5 \mathrm{~h}$. The fatty acid methyl esters (FAME) obtained were purified by adding $5 \mathrm{ml}$ of hexane and $5 \mathrm{ml}$ distilled water to the samples at room temperature. After the shaking, the 
samples were sediment to promote phase separation, $200 \mu \mathrm{l}$ of the organic phase were recovered for analysis by GC-MS.

The samples were analyzed in a chromatograph (Agilent 7890B-GC) coupled to a mass spectrometer (Xevo TQ-S micro) with a Waters Atmospheric Pressure Gas Chromatography (APGC) unit. FAME samples in hexane were injected in splitless mode $(0.5 \mu \mathrm{l})$ at an injector temperature of $250^{\circ} \mathrm{C}$, using a $10 \mu \mathrm{l}$ syringe. An HPInnowax column $(60 \mathrm{mx} 0.25 \mathrm{~mm} \times 0.25 \mu \mathrm{m})$ column was used as stationary phase. Nitrogen (99.999\% purity) was used as carrier gas at a pressure of $10 \mathrm{psi}$, with a flow of $1 \mathrm{ml} / \mathrm{min}$ and an average linear velocity of $30 \mathrm{~cm} / \mathrm{s}$. A mixture of 37 components of FAME (SIGMA-Supelco CRM47885) was used as standard, diluted in septated chromatography vials at a concentration of $1000 \mathrm{ppm}$ with n-hexane (HPLC) and analyzed directly. The oven program was as follows: $60^{\circ} \mathrm{C}$ for $3.5 \mathrm{~min}$, followed by increments of $10^{\circ} \mathrm{C} / \mathrm{min}$ to $200^{\circ} \mathrm{C}$, then increments of $1^{\circ} \mathrm{C} / \mathrm{min}$ to 211 ${ }^{\circ} \mathrm{C}$, which was maintained for $5 \mathrm{~min}$ and then again increments of $2{ }^{\circ} \mathrm{C} / \mathrm{min}$ to 240 ${ }^{\circ} \mathrm{C}$, which was maintained for $7 \mathrm{~min}$. The hexane solvent was detected between minutes 3.5 and 4.5. The ionization of FAME was carried out with argon gas $(99.999 \%)$ at $1 \mathrm{eV}$. The auxiliary temperature was $300{ }^{\circ} \mathrm{C}$, while the temperature of the source was $110^{\circ} \mathrm{C}$. The resolution of the MS was calibrated to a range of 50 to $600 \mathrm{Da}$. The data obtained were processed with the MassLynxTM software (v.4.1). The retention times of each peak were compared with a standard of 37 saturated and unsaturated fatty acids. The ionic fragmentation patterns were determined by MS to verify the identity of the unsaturated fatty acids.

\subsection{Theoretical determination of cetane number in oil from $J$. curcas accessions and F1 hybrids}

The $\mathrm{CN}$ of the oil of each accession was calculated based on the percentage composition of fatty acids in the oil, using the equation suggested by Bamgboye and Hansen (2008).

$C N=61.1+(0.133 * \% C 16: 0)+(0.152+\% C 18: 0)-\left(0.101 *{ }^{*} 16: 1 \Delta^{9}\right)-(0.039$ $\left.{ }^{*} \% \mathrm{C} 18: 1 \Delta^{9}\right)-\left(0.243^{*} \mathrm{C} 18: 2 \Delta^{9,12}\right)-\left(0.395^{*} \mathrm{C} 18: 3\right)$

\subsection{Similarity analysis of accessions concerning their fatty acid composition}

The similarity distance indices among accessions concerning the proportions of fatty acids were calculated using the PAST software (v.3.2), a Euclidean matrix was generated, the dendrogram was constructed with the neighbor-joining method, with the boot of 1000 and final Branch. On the other hand, Pearson's linear correlations were used to analyze the ratio between $\mathrm{J}$. curcas accessions, made using the Pearson index, using the same statistical software (Hammer et al., 2001).

2.5 Characterization and assignment of traits states for fatty acids and classification of accessions and F1 hybrids 
The assignment of trait states was based on the ranges of variation of fatty acid pairs with a linear correlation greater than 0.5 (Table 3 ). The fatty acid pairs that were not detected in at least $30 \%$ of the accessions were discarded. The relationship between fatty acid pairs was considered as a trait, while the range of total variation was the state of the trait. Three traits states were established based on the definition of three sub-ranges, each of which was assigned as a trait state using the following equations:

$\lim s R \|=(R / 3)->((R / 3+R / 3))=$ Trait state II (medium)

$\lim s R I=V \min ->(R / 3)=$ Trait state I (minimum)

$\lim s R I I I=((R / 3+R / 3))->V \max =$ Trait state III (maximum)

Where $\mathrm{R}$ is the total range among all accessions, Vmax is the ratio with the highest value of a pair of fatty acids in all accessions, and Vmin is the ratio with the lowest value of the same fatty acid pair in all accessions.

\section{RESULTS}

\subsection{Analysis of FAP and $\mathrm{CN}$ in oil from $J$. curcas accessions and F1 hybrids}

The fatty acids were esterified in preparation for their identification by GC-MS, using the acid esterification method of Ichihara \& Fukubayashi (2010). This method allowed to detect the presence of fatty acids in the oil from J. curcas accessions, from C4 to C22. In the 24 accessions, the order of occurrence of fatty acids coincided with the 37 FAME mix standard. The presence and the percentage of fatty acids in the oil were used to establish FAP by accession. The FAP was used to calculate the $\mathrm{CN}$, characterizing in this way the oil from each of the 24 accessions. The Table 2 shows the proportion of oleic (C18:1) and linoleic acid $(\mathrm{C} 18: 2)$ is the majority in the FAT of all the accessions, by contrast, C18N6 fatty acids were detected in a minority in two accessions and C18N3 in three accessions. The cetane number of all accessions was higher than that required by the biodiesel quality standards (Ong et al., 2011). 
Table 2. FAP of 9 accessions and $15 \mathrm{~F} 1$ hybrids of $\mathrm{J}$. curcas (\% of total fatty acids).

\begin{tabular}{lccccccccc}
\hline Accession & $\mathbf{C 1 6}$ & $\mathbf{C 1 6 : 1}$ & $\mathbf{C 1 8}$ & $\mathbf{C 1 8 : 1}$ & $\mathbf{C 1 8 : 2}$ & $\mathbf{C 1 8 N 6}$ & $\mathbf{C 1 8 N 3}$ & $\mathbf{C 2 0}$ & $\mathbf{C N}$ \\
\hline JatroP1 & 17.84 & 0.51 & 9.78 & 33.36 & 38.50 & N.D. & N.D. & N.D. & 54.25 \\
JatroP2 & 15.75 & 0.36 & 12.75 & 39.25 & 31.88 & N.D. & N.D. & N.D. & 55.82 \\
JatroP3 & 15.52 & 0.37 & 9.17 & 38.40 & 36.54 & N.D. & N.D. & N.D. & 54.14 \\
JatroP4 & 17.00 & 0.44 & 8.83 & 38.30 & 35.44 & N.D. & N.D. & N.D. & 54.55 \\
JatroP5 & 15.49 & 0.41 & 9.86 & 39.05 & 35.19 & N.D. & N.D. & N.D. & 54.54 \\
JatroP6 & 16.37 & 0.55 & 8.22 & 34.84 & 40.02 & N.D. & N.D. & N.D. & 53.39 \\
JatroT1 & 15.35 & 0.46 & 7.82 & 38.52 & 37.84 & N.D. & 0.03 & N.D. & 53.58 \\
JatroT2 & 15.61 & 0.43 & 7.80 & 40.76 & 35.41 & N.D. & N.D. & N.D. & 54.13 \\
JatroT3 & 16.30 & 0.47 & 9.41 & 42.39 & 31.41 & N.D. & N.D. & 0.01 & 55.37 \\
JatroC1 & 16.32 & 0.51 & 8.12 & 30.39 & 44.67 & N.D. & N.D. & N.D. & 52.41 \\
JatroC2 & 13.64 & 0.43 & 7.89 & 39.94 & 38.03 & 0.03 & 0.05 & N.D. & 53.24 \\
JatroC3 & 14.60 & 0.47 & 8.29 & 40.47 & 36.17 & N.D. & N.D. & N.D. & 53.89 \\
JatroC4 & 15.02 & 0.49 & 7.86 & 39.89 & 36.66 & 0.00 & 0.00 & 0.08 & 53.78 \\
JatroC5 & 15.06 & 0.44 & 8.45 & 35.60 & 40.45 & N.D. & N.D. & N.D. & 53.13 \\
JatroC6 & 13.48 & 0.38 & 8.25 & 41.40 & 36.46 & N.D. & N.D. & 0.03 & 53.63 \\
JatroC7 & 15.28 & 0.46 & 8.47 & 38.90 & 36.89 & N.D. & N.D. & N.D. & 53.89 \\
JatroC8 & 14.21 & 0.53 & 7.28 & 40.92 & 37.06 & N.D. & N.D. & N.D. & 53.44 \\
JatroC9 & 15.13 & 0.43 & 8.03 & 37.47 & 38.93 & N.D. & 0.01 & N.D. & 53.36 \\
JatroC10 & 14.21 & 0.38 & 6.58 & 39.95 & 38.88 & N.D. & N.D. & N.D. & 52.95 \\
JatroC11 & 16.37 & 0.46 & 7.14 & 38.49 & 37.55 & N.D. & N.D. & 0.01 & 53.69 \\
JatroC12 & 13.64 & 0.48 & 6.48 & 39.81 & 39.56 & 0.03 & N.D. & N.D. & 52.68 \\
JatroC13 & 14.00 & 0.43 & 7.28 & 36.14 & 42.16 & N.D. & N.D. & N.D. & 52.37 \\
JatroC14 & 13.18 & 0.33 & 7.60 & 42.47 & 36.40 & N.D. & N.D. & 0.02 & 53.47 \\
JatroC15 & 14.38 & 0.44 & 6.93 & 42.66 & 35.60 & N.D. & N.D. & N.D. & 53.71 \\
\hline
\end{tabular}

C16: Palmitic acid; C16:1: Palmitoleic acid; C18: Stearic acid; C18:1: Oleic acid; C18:2: Linoleic acid; C18N6: $y$-linolenic acid; C18N3: linolenic acid; C20: Arachi-dic acid; N.D: no detected

\subsection{Similarity between $J$. curcas accessions according to the FAP of the oil.}

To assess the potential of fatty acids to be used as a trait, we calculated the Euclidean distance between accessions was calculated concerning their percentage composition of fatty acids, to build a distance dendrogram (Fig. 1). 


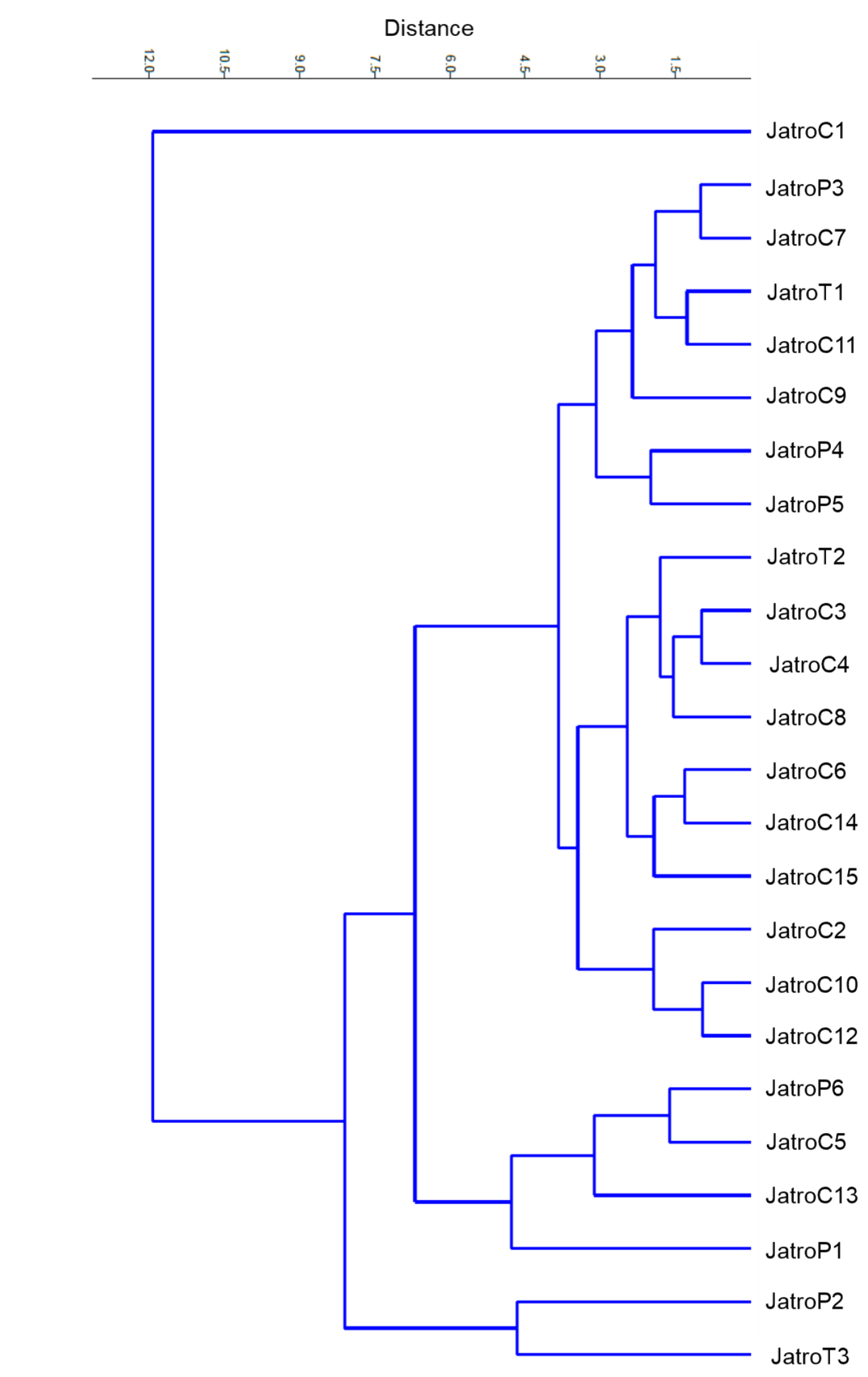

Fig. 1. Clusters of accessions and F1 hybrids by Euclidean distance, based on the composition of fatty acids in the oil of each accession. 
The $\mathrm{CN}$ was not considered since $\mathrm{CN}$ is a chemical property derived from the total composition of fatty acids in the oil and would mask the differences in the amount of each fatty acid. The results showed that the accessions were divided into three well-defined clusters at a distance of 7.5 , where the JatroC1 was completely separated from the rest of the accessions. This hybrid had the highest percentage of linoleic acid and the lowest percentage of oleic acid.

The cluster formed by the JatroP2 and JatroT3 accessions share three fatty acids above average (C18, C16, and C18:1), and fatty acid below average (18:2). In addition to the absence of fatty acids (C18N6 and C18N3). Although the CN was not considered as a differentiating trait between accessions and F1 hybrids, it is worth noting that these two accessions had the highest $\mathrm{CN}$ of all accessions, a further indication of the similarity in the chemical composition of the oil from these accessions.

The third cluster contains four subclusters, one formed by the JatroP6, JatroC5, Jatro $\mathrm{C} 13$ and JatroP1, the latter of which being the most distant from the other accessions and $\mathrm{F} 1$ hybrids in the subcluster and the one that contains the highest percentage of palmitic acid. These subclusters are grouped based on similar average percentages of palmitic acid, oleic acid, and linoleic acid, with no particular fatty acid prevailing over the others (except in JatroP1) and none reaching such high levels as to become part of the other two clusters. Besides the $\mathrm{CN}$ was not considered as a differentiating trait, the third cluster excluded accessions and F1 hybrid with the highest or lowest values of $\mathrm{CN}$, leaving only accessions with intermediate $\mathrm{CN}$ values.

\subsection{Relationship between pairs of fatty acids.}

Since it was proposed that fatty acids could be used as differentiating traits between accessions and $\mathrm{F} 1$ hybrids of $J$. curcas, it was necessary to determine the degree of interdependence between the fatty acids present in J. curcas, it has been demonstrated in other species that the accumulation of some fatty acids negatively influences the accumulation of other fatty acids (Shockey et al., 2017), considering the biochemical pathway of synthesis of fatty acids in plants. For example, varieties with high oleic acid content have low linoleic acid content. For this reason, a correlation analysis between fatty acids was performed using the Pearson index (r).

The correlation analysis between fatty acids (Table 3 ) showed the interdependence of the amount of a fatty acid concerning to the others. Given the biosynthetic relationship between fatty acids, it was considered that Pearson's correlation coefficient values lower than -0.45 and higher than +0.45 denoted enough independence and therefore the possibility of using those pairs of fatty acids as descriptors. Of the relationships between fatty acids that were considered independent, those of $\mathrm{C} 18 \mathrm{~N} 6$ and $\mathrm{C} 18 \mathrm{~N} 3$ were discarded because those fatty 
acids were not detected in all accessions or their content was less than $0.05 \%$. Thus, only the relationships between C16-C18N3 (-0.5481), C18N3-C18N6 ($0.72508)$, C18-C18N6 (-0.50035), C16-C18N6 (-0.81106) and C16-C18 (0.48) were used as a trait.

Table 3. Correlation between fatty acids by Pearson index.

\begin{tabular}{llllllll}
\hline Accession & C16 & C16:1 & C18 & C18:1 & C18:2 & C18N6 & C18N3 \\
\hline C16:1 & 0.417 & & & & & & \\
C18 & 0.486 & -0.188 & & & & & \\
C18:1 & -0.546 & -0.437 & -0.149 & & & & \\
C18:2 & -0.811 & 0.343 & -0.500 & -0.725 & & & \\
C18N6 & -0.359 & 0.036 & -0.216 & 0.118 & 0.121 & & \\
C18N3 & -0.224 & -0.027 & -0.096 & 0.053 & 0.079 & 0.558 & \\
C20 & -0.172 & -0.014 & -0.075 & 0.240 & -0.145 & -0.126 & -0.117 \\
\hline
\end{tabular}

\subsection{Assignment of trait states by categories}

To define the trait states among fatty acid pairs, the ratio between their proportions was first calculated (C18:1N9/C18:2N6, C16/C18, C18:1N9/C16, C18/C18:2N6 y $\mathrm{C} 18: 2 \mathrm{N6} / \mathrm{C} 16)$ to obtain ratio scales (Table 4). The ratio between oleic acid and linoleic acid (C18:1N9/C18:2N6), establish if the vegetal oil is suitable for biodiesel production, therefore, any particular accession of $\mathrm{J}$. curcas should keep this ratio between oleic acid and linoleic acid in desirable proportions (Klopfenstein, 1985; Patil and Deng, 2009; ASTM D6751, 2011). Using the equations described above ( $\lim$ sR II, $\lim$ SR I and $\lim$ SR III), three traits states were defined to classify accessions as low (state I), medium (state II), or high (state III) concerning each trait (Table 4). In crops used for oil production, this classification (high, medium, or low) of a certain fatty acid has been used as a descriptor for varietal differentiation (Rondanini et al., 2011). However, the range of variability in the content of fatty acid is specific to each species (Purdy, 1985; O'Keefe et al., 1993; Shockey et al., 2017); thus, for the accessions of J. curcas evaluated in the present study, specific ranges of variability were established to be able to assign trait states to selected relationships between fatty acids. 
Table 4. Relationship between fatty acids and the assignment of trait states between fatty acids of $J$. curcas.

\begin{tabular}{|c|c|c|c|c|c|c|c|c|c|c|}
\hline \multirow[t]{2}{*}{ Accession } & \multicolumn{2}{|c|}{ C18:1/C18:2 } & \multicolumn{2}{|c|}{ C16/C18 } & \multicolumn{2}{|c|}{ C18:1/C16 } & \multicolumn{2}{|c|}{ C18/C18:2 } & \multicolumn{2}{|c|}{ C18:2/C16 } \\
\hline & $\mathbf{R}$ & $\mathbf{S}$ & $\mathbf{R}$ & $\mathbf{S}$ & $\mathbf{R}$ & $\mathbf{S}$ & $\mathbf{R}$ & $\mathbf{S}$ & $\mathbf{R}$ & $\mathbf{S}$ \\
\hline JatroP1 & 0.866 & I & 1.824 & II & 1.869 & I & 0.254 & II & 2.157 & 1 \\
\hline JatroP2 & 1.231 & III & 1.236 & I & 2.491 & II & 0.399 & III & 2.023 & I \\
\hline JatroP3 & 1.051 & II & 1.692 & II & 2.474 & II & 0.250 & II & 2.354 & II \\
\hline JatroP4 & 1.081 & II & 1.925 & II & 2.253 & I & 0.249 & II & 2.085 & I \\
\hline JatroP5 & 1.11 & II & 1.572 & I & 2.520 & II & 0.280 & II & 2.271 & I \\
\hline JatroP6 & 0.871 & I & 1.992 & III & 2.128 & I & 0.205 & I & 2.444 & II \\
\hline JatroT1 & 1.018 & II & 1.964 & III & 2.509 & II & 0.206 & I & 2.465 & II \\
\hline JatroT2 & 1.151 & III & 2.003 & III & 2.610 & II & 0.220 & I & 2.267 & I \\
\hline JatroT3 & 1.349 & III & 1.732 & II & 2.599 & II & 0.299 & II & 1.926 & I \\
\hline JatroC1 & 0.68 & 1 & 2.011 & III & 1.862 & I & 0.181 & I & 2.737 & III \\
\hline JatroC2 & 1.05 & II & 1.728 & II & 2.929 & III & 0.207 & I & 2.789 & III \\
\hline JatroC3 & 1.119 & II & 1.76 & II & 2.772 & III & 0.229 & I & 2.477 & II \\
\hline JatroC4 & 1.088 & II & 1.912 & II & 2.655 & II & 0.214 & I & 2.440 & II \\
\hline JatroC5 & 0.88 & I & 1.782 & II & 2.363 & II & 0.209 & I & 2.684 & III \\
\hline JatroC6 & 1.135 & III & 1.633 & II & 3.071 & III & 0.226 & I & 2.705 & III \\
\hline JatroC7 & 1.055 & II & 1.804 & II & 2.545 & II & 0.229 & I & 2.413 & II \\
\hline JatroC8 & 1.104 & II & 1.954 & III & 2.878 & III & 0.196 & I & 2.607 & II \\
\hline JatroC9 & 0.962 & II & 1.885 & II & 2.476 & II & 0.206 & I & 2.573 & II \\
\hline JatroC10 & 1.028 & II & 2.161 & III & 2.811 & III & 0.169 & I & 2.735 & III \\
\hline JatroC11 & 1.025 & II & 2.294 & III & 2.351 & II & 0.190 & I & 2.293 & II \\
\hline JatroC12 & 1.006 & II & 2.105 & III & 2.918 & III & 0.163 & I & 2.899 & III \\
\hline JatroC13 & 0.857 & 1 & 1.924 & II & 2.581 & II & 0.172 & I & 3.011 & III \\
\hline JatroC14 & 1.167 & III & 1.735 & II & 3.223 & I & 0.208 & I & 2.762 & III \\
\hline JatroC15 & 1.198 & III & 2.076 & III & 2.967 & III & 0.194 & I & 2.476 & II \\
\hline
\end{tabular}

R: ratio; S: trait state

\section{DISCUSSION}

The ASTM D6751-11b (2011), specifies the properties of biodiesel, establishes a minimum CN value of 47 for biodiesel, for acceptable quality. Lower CN leads to higher NOx emissions and accumulation of soot in the combustion chamber, causing damage to the engine and greater ecological impact. In the present work, the $\mathrm{CN}$ estimation was performed according to the equations proposed by Bamgboye and Hansen (2008), based on the fatty acid composition of the accessions, with an accuracy of $88 \%$. All accessions and F1 hybrids had a CN higher than the established minimum since they had a higher proportion of oleic acid, which is considered appropriate to produce high-quality biodiesel, followed by varieties with a high proportion of saturated fatty acids of long-chain (Klopfenstein, 1985; Sivaramakrishnan and Ravikumar, 2012). 
These fatty acids predominate in $\mathrm{J}$. curcas plants (Table 2), which is consistent with what has been reported by different authors (Campuzano-Duque \& CardeñoLópez, 2020; Ong et al., 2011; Rodrigues et al., 2013). The reduction of shortchain fatty acids is another characteristic that increases the quality of the biodiesel produced. In Table 2, it is observed that the accessions with the least amount of C16 are the product of 13 crosses (Canoira et al., 2010), which suggests that the accessions obtained are suitable to produce biofuel.

To maintain the proportion of fatty acids in the progeny, the use of these as chemical descriptors has been proposed (Ovando-Medina et al., 2011), for this reason, we carried out a study of similarity between parental, control and hybrid accessions about the composition of fatty acids (Fig. 1), using geographically distant and cultivated accessions under the same conditions, however, we did not find a grouping between accessions by geographic region or by progeny. The most influential trait was the proportion of oleic acid and linoleic acid fatty acids.

The above may be due to the degree of variability of the proportions of fatty acids, in additions, the relationship between these fatty acids is based on the biosynthetic route that connects them, the accumulation of fatty acid can negatively influence the accumulation of another due to the presence of genetic and metabolic regulations (Harwood, 1988). This ratio is particularly visible in oleic acid and linoleic acid (Ye et al., 2009). To identify the interdependence between fatty acids, the correlation analysis between fatty acids was performed (Table 3). Correlations that resulted with values less than -45 or greater than 0.45 were proposed as traits, the character states were designated according to the degree of variability (Table $4)$.

Table 4 shows the influence of the fatty acid ratio on the formation of clusters (Fig. 1). Jatro $\mathrm{C} 1$ was independent of the rest of the accessions and $\mathrm{F} 1$ hybrids, and had also the lowest ratio between oleic acid and linoleic acid, with 0.68 , and JatroP2 and JatroT3 formed an independent cluster, with the highest proportion of oleic acid ratio (1.22 and 1.34 respectively). A third cluster divided into three subclusters, one of which included JatroP6, JatroC5, JatroC13 and JatroP1, all classified within the low oleic/linoleic acid category, followed by a subcluster formed by JatroP3, JatroC7, JatroT1, JatroC11, JatroC9, JatroP4 and JatroP5, all classified within the medium category of oleic/linoleic acid, and by a third subcluster formed by JatroC3, JatroC4, JatroC8, JatroC6, JatroC14, JatroC15, JatroC2, JatroC10, JatroC12 and JatroT2, which fell in both the medium and high categories of relationship C18:1/C18:2 (Fig. 1, Table 4).

The use of fatty acids as descriptors in Jatropha is feasible considering the relationship between oleic/linoleic acid, the ratio of palmitic/stearic acid, the ratio of oleic/palmitic acid, the ratio of stearic/linoleic acid and the ratio between linoleic/palmitic acid. By assigning character states concerning the proportional content in pairs of fatty acids, it is possible to follow a genetic improvement route focused on improving the quality of oil in $\mathrm{F} 1$ with a better $\mathrm{CN}$, in addition to being 
able to monitor the modification of this parameter when performing selective crosses and retro crosses of the $\mathrm{F} 1$.

\section{ACKNOWLEDGMENTS}

The authors thank the SAGARPA-CONACYT fund for providing the funds required for the realization of project 163502 , from which this work derives.

We also thank the company "Agroindustria Alternativa del Sureste SPR de RL de CV" for providing the plant material with which the experimental area used in this work was established.

\section{CONFLICT OF INTEREST}

The authors declare that there is no conflict of interest.

\section{REFERENCES}

ASTM D6751-11b. 2011. Standard Specification for Biodiesel Fuel Blend Stock (B100) for Middle Distillate Fuels, American Society for Testing and Materials International, West Conshohocken, PA, www.astm.org. DOI: 10.1520/D6751-11B

Bamgboye A. I., Hansen A. C. \& Hansen A. 2008. Prediction of cetane number of biodiesel fuel from the fatty acid methyl ester (FAME) composition. International Agrophysics. 22: 21-29.

Beyzi E., Gunes A., Buyukkilic Beyzi S. \& Konca Y. 2019. Changes in fatty acid and mineral composition of rapeseed (Brassica napus ssp. oleifera L.) oil with seed sizes. Industrial Crops and Products. 129: 10-14. doi.org/10.1016/J.INDCROP.2018.11.064

Broglie R. M., DeBonte L. R., Hitz W. D., Miao G. H. \& Stefan R. 2006. Methods for increasing oleic acid content in seeds from transgenic plants containing a mutant delta 12 desaturase. U.S. Patent No. 7,109,392B1

Campuzano-Duque, Luis Fernando, \& Cardeño-López, Fernando. (2020). Composición de los ácidos grasos de genotipos de Jatropha curcas L., en Colombia. Agronomía Mesoamericana, 31(1), 95-104. https://dx.doi.org/10.15517/am.v31i1.37574

Canoira, L., García Galeán, J., Alcántara, R., Lapuerta, M., \& García-Contreras, R. (2010). Fatty acid methyl esters (FAMEs) from castor oil: Production process assessment and synergistic effects in its properties. Renewable Energy, 35(1), 208-217. https://doi.org/10.1016/j.renene.2009.05.006

Cruz Rubio B. A., Pérez-Vázquez A., García Perez E., Gallardo Lopez F. \& Soto Hernández R. M. 2015. Comparative chemical-morphological analysis of 
accessions of Jatropha curcas L. from the state of Veracruz. Revista Mexicana de Ciencias Agrícolas. 6: 589-601.

de Carvalho C. G. P., Mazzola L. F., Caldeira A., Dalchiavon F. C. \& Mandarino J. M. G. 2019. Quality of Sunflower Oil Obtained in the Main Producing Region of Brazil: Adherence to the Codex Alimentarius. Journal of the American Oil Chemists' Society. 96: 789-794. https://doi.org/10.1002/aocs.12206

Hammer Ø., Harper D. A. T. \& Ryan P. D. 2001. Paleontological statistics software: package for education and data analysis. Paleontologia Electronica. 4(1): 1-9. http://palaeo-electronica.org/2001_1/past/issue1_01.htm

Harwood, J. L. (1988). Fatty Acid Metabolism. Annual Review of Plant Physiology and Plant Molecular Biology, 39(1): 101-138. https://doi.org/10.1146/annurev.pp.39.060188.000533

Ichihara K. \& Fukubayashi Y. 2010. Preparation of fatty acid methyl esters for gasliquid chromatography. Journal of Lipid Research. 51: 635-40. https://doi.org/10.1194/jlr.D001065

King, A. J., He, W., Cuevas, J. A., Freudenberger, M., Ramiaramanana, D., \& Graham, I. A. (2009). Potential of Jatropha curcas as a source of renewable oil and animal feed. Journal of experimental botany. 60(10): 2897-2905.

Klopfenstein W. 1985. Effect of molecular weights of fatty acid esters on cetane numbers as diesel fuels. Journal of the American Oil Chemists' Society. 62: 10291031. https://doi.org/10.1007/BF02935708

Montes O. L. R., Torres S. A. F., Jongschaap R. E. E., Azurdia P. C. A., Berduo, S. J. E., Trindade L. M., Visser R. G. F. \& van Loo E. N. 2014. High level of molecular and phenotypic biodiversity in Jatropha curcas from Central America compared to Africa, Asia and South America. BMC Plant Biology. 14:77. https://doi.org/10.1186/1471-2229-14-77

Nakkash N. B. \& Al-karkhi S. R., 2012. Production of biodiesel fuel from oleic acid and comparison of its properties with petroleum diesel. Iraqi Journal of Chemical and Petroleum Engineering. 13(4): 13-25.

O'Keefe S. F., Wiley V. A. \& Knauft D. A. 1993. Comparison of oxidative stability of high- and normal-oleic peanut oils. Journal of the American Oil Chemists' Society. 70: 489-492. https://doi.org/10.1007/BF02542581

Ong H. C., Mahlia T. M. I., Masjuki H. H. \& Norhasyima R. S. 2011. Comparison of palm oil, Jatropha curcas and Calophyllum inophyllum for biodiesel: A review. Renewable and Sustainable Energy Reviews. 15: 3501-3515. https://doi.org/10.1016/j.rser.2011.05.005 
Ovando-Medina, I., Espinosa-García, F. J., Núñez-Farfán, J., \& Salvador-Figueroa, M. (2011). Genetic variation in Mexican Jatropha curcas L. estimated with seed oil fatty acids. Journal of Oleo Science, 60(6), 301-311. https://doi.org/10.5650/jos.60.301

Patil P. D. \& Deng S. 2009. Optimization of biodiesel production from edible and non-edible vegetable oils. Fuel 88(7): 1302-1306. https://doi.org/10.1016/j.fuel.2009.01.016

Purdy R. H. 1985. Oxidative stability of high oleic sunflower and safflower oils. Journal of the American Oil Chemists' Society. 62: 523-525. https://doi.org/10.1007/BF02542324

Ramos M. J., Fernández C. M., Casas A., Rodríguez L. \& Pérez Á. 2009. Influence of fatty acid composition of raw materials on biodiesel properties. Bioresource Technology. 100(1): 261-268. https://doi.org/10.1016/j.biortech.2008.06.039

Rashed M. M., Kalam M. A., Masjuki H. H., Rashedul H. K., Ashraful A. M., Shancita I. \& Ruhul A. M. 2015. Stability of biodiesel, its improvement and the performance and emission. Royal Society of Chemistry Advances. 5: 3624036261. https://doi.org/10.1039/C4RA14977G

Rodrigues J., Miranda I., Gominho J., Vasconcelos M., Barradas G., Pereira H., Bianchi-de-Aguiar F. \& Ferreira-Dias S. 2013. Variability in oil content and composition and storage stability of seeds from Jatropha curcas L. grown in

Mozambique. Industrial Crops and Products. 50: 828-837. https://doi.org/10.1016/J.INDCROP.2013.08.038

Rondanini B. D. P., Castro D. N., Searles P. S. \& Rousseaux M. C. 2011. Fatty acid profiles of varietal virgin olive oils (Olea europaea L.) from mature orchards in warm arid valleys of Northwestern Argentina (La Rioja). Grasas y Aceites 62(4): 399-409.

Sánchez-Velázquez, J. U., Pacheco, N., López-Puc, G., \& Ramos-Díaz, A. (2018). Behavior of genetic diversity in $\mathrm{F} 1$ crosses of selected accessions of $\mathrm{J}$. curcas. Industrial Crops and Products. 122: 669-674. https://doi.org/10.1016/j.indcrop.2018.05.029

Shalaby E. A. 2015. A Review of Selected Non-Edible Biomass Sources as Feedstock for Biodiesel Production. Biofuels-Status and Perspective. 30: 3-20. DOI: $10.5772 / 59178$

Shockey J., Dowd, M., Mack B., Gilbert M., Scheffler B., Ballard L., Frelichowski J. \& Mason C. 2017. Naturally occurring high oleic acid cottonseed oil: identification and functional analysis of a mutant allele of Gossypium barbadense fatty acid desaturase-2. Planta 245: 611-622. https://doi.org/10.1007/s00425-016-2633-0 
Sivaramakrishnan K. \& Ravikumar P. 2012. Determination of cetane number of biodiesel and it's influence on physical properties. Asian Research Publishing Network Journal of Engineering and Applied Sciences. 7(2): 205-211.

Teo S. H., Islam A., Chan E. S., Thomas Choong S. Y., Alharthi N. H., Taufiq-Yap, Y. H. \& Awual M. R. 2019. Efficient biodiesel production from Jatropha curcas using $\mathrm{CaSO}_{4} / \mathrm{Fe}_{2} \mathrm{O}_{3}-\mathrm{SiO}_{2}$ core-shell magnetic nanoparticles. Journal of Cleaner Production. 208: 816-826. https://doi.org/10.1016/J.JCLEPRO.2018.10.107

Ye J., Qu J., Bui H. T. N. \& Chua N. H. 2009. Rapid analysis of Jatropha curcas gene functions by virus-induced gene silencing. Plant Biotechnology Journal. 7(9): 964-976. https://doi.org/10.1111/j.1467-7652.2009.00457.x 